\title{
O corpo e a construção das desigualdades de gênero pela ciência
}

\section{| ${ }^{1}$ Maria das Graças Melo Fernandes |}

Resumo: Este trabalho analisa, a partir de uma revisão bibliográfica assistemática, como a distinção entre o corpo masculino e o feminino produzida pela ciência desde o século XIX, especialmente pelo discurso e prática médica, enunciadores legítimos dos desígnios naturais dos corpos, vem contribuir para a construção de uma inferioridade do corpo feminino que legitima desigualdades de gênero vigentes nas sociedades tradicionais que, de algum modo, ainda se reproduzem ou permanecem na contemporaneidade.

> Palavras-chave: corpo; sexo; gênero.
1 Professora Adjunta do Departamento de Enfermagem Médico-Cirúrgica e

Administração da Universidade Federal da Paraíba. Doutora em Ciências da Saúde e em Sociologia pela UFPB. Endereço eletrônico: gracafernandes@ hotmail.com

Recebido em: 04/02/2009 Aprovado em: 19/10/2009. 
No domínio da objetividade das ciências naturais, o corpo humano é matéria conformada numa organização social exclusiva e determinada, constituindo a individualidade de cada ser. No domínio da subjetividade, trata-se de um corpo sujeito que se apresenta, que fala de si, que se representa na história.

Segundo Rodrigues (2006), não se pode compreender a natureza do homem apenas em termos de natureza, pois, na mesma matéria, coexistem um corpo biológico e um corpo social. Outra abordagem que se refere à natureza social da experiência física do corpo é dada por Gastaldo (2001), que considera a existência de "dois corpos", um físico e outro social, em profunda interação.

Considerando isso, o corpo humano, como sistema biológico, é afetado pela religião, pela classe, pelo grupo familiar, pelo gênero e por outros intervenientes sociais e culturais, cumprindo também uma função ideológica (RODRIGUES, 2006). Esse processo é denominado pelo autor de "apropriação social do corpo" (anatômico e fisiológico, em princípio). Assim, como afirma Featherstone (1994), os corpos não operam no mundo social como coisas "em si mesmas", ao contrário, a sua capacidade de operar é mediada pela cultura, ou seja, apesar de todos os seres humanos terem corpos, estes são representados, usados, controlados e concebidos de acordo com a cultura (NOVAES, 2006).

Nesse cenário, é possível entender o corpo como resultado provisório de diversas pedagogias que o conformam em determinadas épocas e lugares, que adquire diferentes sentidos no momento em que é investido por um poder regulador que o ajusta em seus detalhes, impondo limitações, autorizações e obrigações, para além de sua condição fisiológica. Considerando essa perspectiva, o corpo encarna as concepçôes que orientam determinada sociedade, modificando-se conforme as transformações que ocorrem nesse contexto. Essas concepções são produzidas através dos diferentes saberes e práticas sociais, as quais produzem efeitos e instituem verdades, excluindo e incluindo corpos sujeitos e grupos (MATOS; LOPES, 2008).

Imbuída desse entendimento, realizamos, neste escrito, uma breve análise sobre a contribuição do conhecimento científico, particularmente da ciência médica, produzido especialmente no século XIX, para a representação do corpo feminino como incompleto, doente e instável e, consequentemente, para a construção das desigualdades de gênero, ainda presentes na atualidade. 


\section{O corpo como diferença: o feminino e o masculino}

Numa análise da evolução dos conceitos de corpo e gênero, dos gregos até o século XX, Thomas Laqueur (1991) afirma ter havido modificações fundamentais nos modos como nós vemos o corpo masculino e o corpo feminino. Ele argumenta que, até o século XVIII, o discurso dominante construiu os corpos masculino e feminino como versões hierárquicas e verticalmente ordenadas de um único sexo.

Corroborando tal assertiva, Costa (1996) ressalta que, até o século XVIII, o pensamento filosófico e médico da Europa acreditava na existência de um só sexo, o masculino. A mulher era o seu representante inferior, sendo descrita como um homem invertido. Havia uma relação da continuidade e hierarquização determinada pelo grau de perfeição metafísica. O homem era portador do calor vital que o fazia evoluir para a forma superior de macho com a exteriorização de seus órgãos genitais e, na mulher, a ausência desse calor impossibilitava tal exteriorização, determinando a posição de inferioridade. Haveria, então, um só corpo, uma só carne, na qual se aplicavam distintas marcas sociais ou inscrições culturais, conforme seu nível de perfeição.

Essa concepção mudou no final do século XVIII, quando foi demarcada a criação da bissexualidade. É através da mudança do modelo de sexo-único para o modelo mais científico de dois sexos que Laqueur (2001) demonstra a construção das diferenças, modificando radicalmente a interpretação dos corpos masculino e feminino - sendo este associado a metáforas negativas e patológicas. Nesse contexto, o corpo da mulher tornou-se o campo de batalha para redefinir a relação social fundada entre homem e mulher, incluindo os distintivos morais sobre o corpo e a sexualidade, passando a ser enfocado pelas "tecnologias individualizantes do poder".

Assim,

o mundo social constrói o corpo como uma realidade sexuada e como depositário de princípios de visão e de divisão sexualizante. Esse programa social de percepção incorporada aplica-se a todas as coisas do mundo e, antes de tudo, ao próprio corpo, em sua realidade biológica (BOURDIEU, 1999, p. 19-20).

Considerando essa perspectiva, Rohden (2001) salienta que a medicina, por meio de seus saberes particulares ou auxiliares, a exemplo da anatomia, da biologia e da psiquiatria, começa a fornecer os argumentos necessários à transposição para o mundo da corporalidade de demarcações morais justificatórias de novas 
hierarquizações dos seres humanos. Nesse cenário, estruturas, como o esqueleto e o sistema nervoso, que antes eram comuns, agora, por meio de uma "anatomia política", são diferenciadas, salientando uma inferioridade do corpo feminino.

Essa diferença de natureza entre o corpo masculino e feminino, associada a uma anatomia particular, caracterizando o corpo da mulher como inferior, é ratificada por Londa Schiebinger no artigo "Esqueletos no Armário: as primeiras representações do esqueleto feminino na anatomia do século XVIII”. Nesse escrito, a autora desvenda quão profundamente a perspectiva de desigualdade entre os sexos atingiu os estudos de anatomia, no sentido de desmerecer as mulheres em relação aos homens (SCHIEBINGER, 1987). É o caso da assertiva de que a mulher tinha o crânio menor, consequentemente, menor capacidade intelectual, bem como a constatação de que ela possuía a pelve maior, sendo por isso "naturalmente destinada à maternidade".

Do mesmo modo, Martin (1996), examinando textos utilizados em cursos de medicina até meados do século XX, aponta o contraste presente na linguagem científica para descrever a relação entre o espermatozóide - invariavelmente ativo, ágil, com caudas rápidas e fortes - e o óvulo - passivo, à espera do espermatozóide, depois de fecundado, segue a deriva pela trompa de Falópio, quase uma bela adormecida. Posteriormente, em três estudos efetivados nos anos 80, Martin (1996) localizou achados que, à primeira vista, permitiriam inverter o imaginário sexista sobre o óvulo; no entanto, a tenacidade dos estereótipos de gênero parece não ter permitido a inversão. Ao contrário, salienta a autora, permitem levá-los para o nível das células, fazendo as mulheres parecerem ainda mais naturais.

Discorrendo sobre isso, Matos (2003) destaca que a construção de uma diferença de natureza entre o corpo masculino e feminino implicou um corpo particular às mulheres, visto de modo essencializado: arredondado, volumoso, seios generosos, ancas desenvolvidas, qualidades associadas a um corpo materno. A beleza ideal da mulher era delineada em função da maternidade. Ampliando essa análise, Grosz (2000) explica que, apoiando-se no essencialismo, no naturalismo e no biologismo, o pensamento misógeno confina as mulheres às exigências biológicas da reprodução, na suposição de que, em virtude de certas transformações biológicas, fisiológicas e endocrinológicas específicas, as mulheres, de algum modo, são mais corporais e mais naturais do que os homens. 
As particularidades biológicas diagnosticadas pelos cientistas passam a oferecer

a base para que pensadores sociais dissertem sobre as supostas diferenças inatas entre homens e mulheres e a consequente necessidade de diferenciações sociais. A natureza já se tinha encarregado de postular a divisão e caberia à sociedade respeitá-la e promover um comportamento adequado (ROHDEN, 2003).

Nesse cenário, o sistema reprodutivo feminino constituía a base da função social da mulher e de suas características comportamentais, produzindo um ser mais frágil do ponto de vista físico, intelectual e emocional. Esse discurso impingiu à mulher a representação que a desqualifica enquanto pessoa e a subordina a uma matriz biológica e procriadora. Para Martin (2006), essa maneira de pensar o corpo feminino se deve a uma alienação da ciência e da produção do conhecimento científico ligada à objetividade e outros valores, que a autora aponta como masculinos.

Segundo Rohden (2003), no século XVIII imaginava-se que, em cada indivíduo, aconteceria uma luta interna entre os elementos considerados masculinos (como a razão) e aqueles percebidos como femininos (como a emoção). Em termos de estereótipos, os homens seriam sérios e pensativos, e as mulheres, frívolas e emotivas. Nesse pensamento, a inteligência, a mais nobre manifestação da sensibilidade e expressão do direito de dominação sobre a natureza, estaria associada ao masculino.

Tais concepções são referendadas em 1789 pela Declaração Francesa dos Direitos do Homem e do Cidadão, ao excluir as mulheres de direitos civis e políticos por sua aproximação com a natureza e debilidade intelectual. No século XIX, insiste-se

na existência de duas "espécies" com qualidades e aptidões particulares. Aos homens, o cérebro (muito mais importante do que o falo), a inteligência, a razão lúcida, a capacidade de decisão. Às mulheres, o coração, a sensibilidade, os sentimentos (PERROT, 1992, p. 177).

Assume-se que o homem é o indivíduo forte e que, com sua agressividade e inteligência, impôs o desenvolvimento da civilização urbana, ao passo que a mulher, por sua natureza passiva e fecunda, deve perpetuar essa civilização através da maternidade. A incapacidade e/ou recusa desse papel por parte da mulher definiria um caráter desviante, estranho à própria natureza. A fragilidade física da mulher a tornaria inapta para se expor aos perigos do mundo exterior, enquanto sua 
fragilidade mental implicaria a incapacidade de atuar satisfatoriamente na esfera pública. Também as características psicológicas vistas com maior positividade, como a capacidade de amar e emocionar-se, compunham uma compleição perfeita para o cuidado das crianças e a privacidade do lar (BELLINI, 2003).

Em outras palavras, a especificidade corporal das mulheres é usada para explicar e justificar as posiçōes sociais e as capacidades cognitivas inferiores atribuídas às mulheres. Por implicação, os corpos das mulheres são presumidamente incapazes das realizações masculinas, sendo mais fracos, mais expostos a irregularidades (hormonais), intrusões e imprevistos (GROSZ, 2000).

Sant'Anna (2006) salienta que, desde há muito, as mulheres são consideradas seres passivos, submetidos ao destino da fecundidade. Na sociedade romana, a mulher era considerada passiva por definição. A moral dos gregos antigos, do mesmo modo, resultava de uma sociedade essencialmente viril na qual a mulher, ser passivo por natureza e por estatuto, assim como o escravo, deveria se manter sob a proteção e a dominação de um homem. Assim, opera-se uma construção sociocultural da feminilidade que Simone de Beauvoir analisou em sua obra o Segundo sexo, escrita em 1949, feita de contenção, discrição, doçura, passividade, submissão, pudor, silêncio (BEAUVOIR, 1980).

Em seus trabalhos orientados em direção a uma "genealogia do sujeito," sujeito moral e sujeito do desejo, Foucault $(1990,1994)$ sublinha que, no amor entre os homens da Grécia antiga, o problema consistia em não se admitir o fato de um jovem (futuro cidadão livre) se comportar como um ser passivo, tal como uma mulher e um escravo. $\mathrm{O}$ amor entre os homens não era necessariamente considerado antinatural. Ele era problemático quando o futuro cidadão nele tivesse uma atitude passiva.

Essa representação negativa do feminino também envolve as etapas do desenvolvimento da mulher, as quais são menos ritualizadas e solenizadas do que as dos rapazes. No século XIX, a adolescência masculina é considerada uma crise; a das meninas, uma mutação suave que as encaminha ao papel de reprodutoras. $\mathrm{Na}$ senescência, a menopausa ocorre numa semiclandestinidade. No senso comum, uma mulher na menopausa já não é mulher, e sim uma velha, eventualmente dotada de mais poderes e liberdades, porém privada da fecundidade (PERROT, 2003), imaginário que ainda está fortemente por ser desconstruído.

Considerando essa questão, Swain (2003) ressalta que hoje certos discursos médicos relativos à menopausa promovem a recriação do corpo doente (todas 
histéricas!), por definição, feminino. Para as “jovens”, a autora salienta que essa reapropriação do corpo é realizada pelos discursos da TPM (tensão pré-menstrual), que reduz as mulheres a seus hormônios - é o império do "corpo hormonal". Já a puberdade é apontada como um momento crucial da diferenciação sexual, descrita como uma verdadeira crise médica na qual a ordem biológica de cada indivíduo é rearranjada, ou seja,

\begin{abstract}
a menina experimenta uma recanalização de seus fluidos vitais para um novo centro, o útero. Entretanto, essas transformaçōes não fazem com que ela avance muito além da constituição que tinha como criança. Ela continua frágil, terna, retendo algo do temperamento infantil [...]. O menino púbere sofre mudanças que anuncia o seu destino natural. O seu corpo torna-se mais forte, sua face e sua voz tornam-se masculinas, da mesma forma que o seu caráter. Tudo nele caracteriza o sexo que tem por função proteger (VILA, 1995, p. 79).
\end{abstract}

A diferenciação corporal nesse pressuposto sexista também se dá no âmbito do sistema nervoso, onde haveria uma distinção entre as partes frágeis ou femininas e as partes fortes ou masculinas. $\mathrm{O}$ cérebro era descrito como a parte mais masculina do sistema nervoso. Enquanto a capacidade de melhorar e expandir seria uma condição normal e natural da mente masculina, não se daria o mesmo na mente feminina (ROHDEN, 2003).

Segundo Fausto (1846), a mulher, ao realizar esforço mental excessivo, corre o risco de provocar uma modificação na natureza de seu temperamento, pois é feita para a família e não pode se envolver em estudos intensivos, como faz o homem. A dedicação aos estudos, acrescenta o autor, pode fazer com que todas as energias que deveriam ser empregadas no amadurecimento do aparelho reprodutor sejam desviadas para o cérebro. Isso pode causar tanto o retardo no aparecimento da primeira menstruação, como problemas para aquelas já "regradas", podendo ainda gerar crianças doentes ou malformadas. Desse modo, a diferença, apesar de natural, é passível de ameaças do mundo da cultura, particularmente da educação.

Segundo Rohden (2003), o médico José Tavares de Mello, em seu trabalho "A higiene da mulher durante a puberdade e aparecimento do fluxo catamenial", realizado em 1841, é ainda mais enfático ao condenar a aplicação intelectual das mulheres. Justifica sua posição não só pela teoria do desvio das forças ao cérebro, mas também em função do lugar que a mulher ocupava na sociedade:

tristes exemplos atestam todos os dias a inutilidade, e até o perigo de obrigar as meninas à cultura das ciências, e demonstram os inconvenientes de uma aplicação muito sustentada, e a perniciosa influência que ela exerce sobre a saúde. A excitação prolon- 
gada do cérebro não se limita só a fazer dele o centro exclusivo de ações e movimentos, enfraquecendo a energia dos outros órgãos; mas o força também a tornar-se a sede de uma susceptibilidade, que ocasiona cefalgias, doenças nervosas, e outras muitas afecções, que envenenam os mais belos dias das mulheres [...] A espécie de império, que exercem na sociedade, exigem que elas não sejam ignorantes; porém não lhes é devido o mesmo grau de instrução dos homens, cujos destinos partilham e embelezam. O estudo moderado das artes de recreação é o único que lhes convém; porém somente como meio de adoçar as tristezas, suavizar o aborrecimento da solidão, lançar sobre o curso de sua vida doces e agradáveis distraçôes, de variar enfim os prazeres distraindo-as em seus trabalhos (MELLO, 1841 apud ROHDEN, 2003, p. 210).

Conforme se verifica, há uma distribuição das qualidades físicas e morais baseada no gênero e uma impressão deste em sistemas e órgãos. Desse modo, associados a uma anatomia particular, surgiram também comportamentos morais, legitimados ao longo do tempo pelo discurso médico, religioso e político. Conforme argumenta Matos (2003), os novos métodos de interpretar o corpo nesse período significaram novos modos encontrados por filósofos e moralistas do Iluminismo de representar e constituir realidades sociais. Frente a essa realidade, o gênero parecia irremediavelmente colado ao sexo numa única e invariável direção.

No espaço público, a mulher deve ocultar ao máximo suas partes íntimas. A conveniência ordena às mulheres da boa sociedade que sejam discretas, que dissimulem suas formas com códigos (variáveis, segundo o lugar e o tempo). O peito, as pernas, os tornozelos, a cintura constituem objeto de censuras que traduzem as obsessões eróticas de uma época e se inscrevem nas imposições da moda. Os cabelos, signo supremo da feminilidade, devem ser disciplinados, cobertos, por vezes, com véu. A mulher decente não deve erguer a voz. $\mathrm{O}$ sorriso é limitado. Em certas ocasiões, pode chorar, coisa proibida ao homem. Sua aparência deve exprimir a fortuna do marido - consumo vicário. O homem rico gosta de ostentar a beleza de sua(s) amante(s), o que glorifica sua virilidade (PERROT, 2003).

A expressão da enfermidade também ocorria de forma diferenciada, a depender do sexo da pessoa. Considerando as mulheres, segundo Peter (1980), sua própria existência normal já as confundia com seres doentes e por isso eram chamadas por alguns de "patologias ambulantes". Isto se dava em função da série de fenômenos que transformavam suas vidas constantemente, como gravidez e "hemorragias periódicas". 
Do mesmo modo, o trato das doenças também tinha abordagens distintas, considerando as especificidades masculina e feminina. No que se refere aos problemas de natureza física, os diagnósticos para sintomas idênticos eram totalmente diferentes para homens e mulheres. A análise médica sobre a mulher tinha como base um órgão - o útero - a partir do pressuposto de que qualquer desequilíbrio nesse órgão poderia provocar reações patológicas em outras áreas do corpo. Quanto à cura, havia alguns encaminhamentos comuns a ambos os sexos, como o isolamento e o repouso; todavia, às enfermidades femininas, na maioria das vezes aplicava-se tratamento local, diretamente na vagina e no colo do útero - injeções, cauterizações, ferro quente, sanguessugas (MATOS, 2003).

Os textos produzidos por médicos, descrevendo suas experiências terapêuticas, deixam entrever uma prática ginecológica punitiva das mulheres por suas próprias enfermidades, principalmente venéreas, de modo que o processo de cura deveria ter um caráter regenerador e punitivo. Nesses textos, as enfermidades femininas são vistas tanto como sinônimo de fragilidade, quanto como incapacidade do exercício de suas funções como mãe e esposa. Assim, apesar de propalar toda uma neutralidade em relação ao corpo da paciente-mulher, esse discurso científico sugeria a existência de um poder superior do médico-homem (MATOS, 2003).

Segundo o autor medievalista Le Goff (1991), o corpo da mulher, além de ser lócus de muitas enfermidades relativas à sua natureza, também tinha o potencial de propagar doenças para outros, dependendo da sua condição: o período da menstruação, por exemplo, era atravessado por tabus - os leprosos eram tidos como filhos daqueles que mantiveram relaçôes sexuais quando a mulher estava menstruada. Isto é, a menstruação aparece como perigosa e nociva. Tomás de Aquino, por exemplo, relacionou o sangue menstrual à impureza. Para ele, a mulher, nessa fase, não deveria manter relações sexuais, exceto quando o marido exigisse (SILVA; MANDÚ, 2007).

Vale salientar que a identificação das mulheres com a impureza está presente em ideias religiosas que antecederam Platão ou que lhe foram contemporâneas. Nestas, o coito e o nascimento são vistos como atividades poluidoras, e só os rituais de purificação poderiam limitar sua contaminação (SCHOTT, 1996). Vale salientar que essa impureza feminina, especialmente dos seus humores, também é ratificada tanto pelo conhecimento do senso comum quanto pelo saber médico, quando as mulheres, entre 1920 e 1950, foram acusadas de 
envenenarem seus filhos com leite "estragado" tendo como explicação o fato de estarem menstruadas durante a amamentação, sentirem libido ou terem relações sexuais fogosas, irritação, cansaço e outros (FINE, 2003).

Quanto às doenças "do espírito" ou da mente, Engel (2007) ressalta que o corpo e a sexualidade das mulheres eram remetidos ao lugar da loucura, à crença de que na sua fisiologia estaria inscrita uma predisposição à doença mental. Falavase inclusive na "loucura menstrual". Haveria uma especificidade na condição feminina diante da loucura. Enquanto a mulher era diagnosticada como doente mental como resultado de desvio em sua natureza, sobretudo sexual, o homem, quando acometido por tal distúrbio, resultava dos desvios relativos aos seus papeis sociais de trabalhador e de provedor.

Frente a essa pressuposição, os psiquiatras compartilhavam a ideia de que a maternidade, vista como a verdadeira essência das mulheres, constituía um dos remédios mais eficazes para prevenir e curar os distúrbios mentais. Assim, as mulheres que não podiam ou não desejavam ter filhos eram consideradas incapazes física, moral ou psiquicamente. Estas mulheres acabariam experimentando algum tipo de insanidade ao longo de suas vidas.

Conforme Bordo (1997) e Perrot (2003), durante muito tempo (com variações históricas), as mulheres foram consideradas nervosas, histéricas, atacadas de "lipemania" (segunda metade do século XIX), agorafóbicas - confinadas a casa -, anoréxicas e portadoras de bulimia (segunda metade do século XX). A histerização da mulher imprime-lhe a condição de corpo saturado de sexualidade que, vista como patologia intrínseca, lhe insere no campo das práticas médicas.

O corpo das mulheres "doentes" representa o corpo profundamente marcado por uma construção ideológica da feminilidade típica dos períodos em questão. A sintomatologia evidenciada por essas mulheres, conforme pontuam as autoras feministas, constituía, muitas vezes inconscientemente, um caminho através do qual as mulheres "convencionais" podiam expressar a insatisfação com o seu estilo de vida (BORDO, 1997). Ohrbach (1985), por exemplo, interpreta anorexia como uma espécie de protesto feminista inconsciente através do qual as mulheres manifestavam corporalmente o que não deviam expressar com palavras. Por outro lado, através da anorexia, a mulher descobre inesperadamente uma entrada para o privilegiado mundo masculino, isto é, exclui-se da associação cultural de um corpo feminino curvilíneo com incompetência (BORDO, 1997). Acrescenta 
a autora (p. 26): "na busca pela esbeltez e na negação do apetite, a construção tradicional da feminilidade cruza com a nova exigência para as mulheres de incorporar os valores 'masculinos' da área pública”.

Nesse cenário, as mulheres jovens "em ascensão", ao se engajarem em atividades profissionais, precisam aprender a incorporar a linguagem e os valores "masculinos" desse âmbito - autocontrole, determinação, disciplina, domínio, entre outros. "Os corpos femininos falam agora dessa necessidade em sua configuração corpórea, reduzida, enxuta, e no uso de roupa mais próxima da masculina, em moda atualmente" (BORDO, 1997, p. 26).

$\mathrm{O}$ alcance de tal meta requer o aperfeiçoamento do corpo como um objeto, emergindo, assim, um comportamento feminino convencional. Segundo Bordo (1997), nesse contexto pode-se afirmar que o convencionalismo feminino "se desconstrói”, transformando-se em seu oposto e aglutinando valores que nossa cultura codificou como masculinos. Para a autora, essa experiência de poder é ilusória e perigosa, pois remodelar um corpo para torná-lo mais masculino não é ganhar poder e privilégios masculinos. Em busca desse ideal, os corpos femininos podem se encontrar tão desalentados e fisicamente enfermos quanto os corpos femininos do século XIX.

Não obstante, na época contemporânea as coisas mudam, o foco se modifica. O corpo em geral, o corpo da mulher em particular, por ser estratégico no jogo democrático, passa a ser um centro de saberes mais apurados, de poderes mais articulados e, consequentemente, lugar de um discurso superabundante, destacandose principalmente o feminino, conforme aponta Perrot (2003, p. 26):

nosso corpo, nós mesmas - direitos ao corpo, conhecimento do corpo, livre disposição do corpo na procriação e na relação amorosa. $\mathrm{O}$ silêncio vencido. Isso não significa que tudo esteja resolvido, continuam existindo imensas zonas de sombra e de silêncio em todo o mundo.

Um dos exemplos dessa zona de silêncio relativa ao domínio e à violência sobre o corpo da mulher, segundo Miller (1999), verifica-se na China, onde o governo defende a esterilização forçada e o aborto para manter a lei do filho único, além de ignorar os milhares de bebês do sexo feminino que são mortos porque os meninos são considerados mais valiosos. No Sudão e na Somália, pratica-se a mutilação do clitóris. No Congo e em grande parte da região norte da África, o adultério é ilegal somente para as mulheres, e não para os homens. 
Talvez as razões envolvidas na gênese dessa violência dirigida ao corpo da mulher possam, de algum modo, ser agregadas ao argumento elaborado por Citeli (2001), o qual nos convida a perceber que os estereótipos construídos com base em metáforas de ordem biológica têm demonstrado uma grande tenacidade ou constância ao longo do tempo, apesar das inconsistências que vão acumulando perante mudanças sócio-culturais, tecnológicas e políticas. Isso acontece devido a algumas vertentes do conhecimento que insistem em exagerar diferenças para encontrar, nos corpos, sustentabilidade para interpretaçõos deterministas de comportamentos e crenças humanas envolvidos na demarcação de uma superioridade ou inferioridade feminina ou masculina (CITELI, 2001). Considerando o feminino, a autora salienta a emergência de estudos produzidos, especialmente por feministas, no âmbito da biologia física e da antropologia, que desconstroem metáforas de gênero que desvalorizavam as mulheres, identificando que estas são mais fortes, mais resistentes e mais ativas sexualmente do que se imaginava. Desse modo, essas mulheres tornam o campo científico mais justo e menos androcêntrico.

\section{Ponderações finais}

Ante o exposto, verifica-se como as relações sociais de gênero são "gendradas" ou marcadas por especificidades de gênero (LAURETIS, 1994) e, como, consequentemente, alcançam o corpo, já que o gênero "é uma maneira de existir do corpo, sendo este uma situação, isto é, um campo de possibilidades culturais recebidas e reinterpretadas (SAFFIOTI, 1992).

Nesse campo de possibilidades culturais em que o corpo pode ser afetado, o saber médico emergiu como alicerce ideológico à cristalização dessas relaçoos sociais de gênero "gendradas", contribuindo para que as principais decisões políticas obtivessem sucesso, ancoradas nas diferenças corporais verificadas entre homens e mulheres, oferecendo a estas um campo social delimitado restrito e utilitarista, moldando-as de acordo com as normas sociais observadas em determinados contextos e épocas.

\section{Referências}

BEAUVOIR, S. de. O segundo sexo. Rio de Janeiro: Nova Fronteira, 1980.

BELLINI, L. Concepçóes do corpo feminino no Renascimento: a propósito de De universa mulierum medicina, de Rodrigo Castro (1603). In: MATOS, M.I.S. de.; SOIHET, R. (Org.). Corpo feminino em debate. São Paulo: UNESP, 2003. p. 14-29. 
BORDO, S.R. O corpo e a reprodução da feminilidade: uma apropriação feminista de

Foucault. In: BORDO, S.R.; JAGGAR, A.M. Gênero, corpo, conhecimento. Rio de Janeiro: Rosa dos Tempos, 1997. p. 19-38.

BOURDIEU, P. A dominação masculina. Rio de Janeiro: Bertrand Brasil, 1999.

CITELI, M.T. Fazendo diferenças: teorias sobre gênero, corpo e comportamento. Estudos Feministas, v. 9, p. 131-145, 2001.

CORRÊIA, J. de A. O presente da velhice: reflexão filosófica sobre a velhice. Rio de Janeiro: Guanabara, 1999.

COSTA, J.F. O referente da idade homossexual. In: PARKER, R.; BARBOSA, R.M. (Org.). Sexualidades brasileiras. Rio de Janeiro: Relume-Dumará, 1996. p. 63-89.

ENGEL, M. Psiquiatria e feminilidade. In: DEL PRIORI, M. (Org.). História das mulheres no Brasil. 9. ed. São Paulo: Contexto, 2007. p. 322-361.

FAUSTO, J.O. Acerca da menstruação, seguida de regras higiênicas relativas às mulheres menstruadas. 1846. 142f. Tese (Mestrado em Medicina) - Faculdade de Medicina do Rio de Janeiro, Rio de Janeiro.

FEATHERSTONE, M. O curso da vida: corpo, cultura e imagens do processo de envelhecimento. In: DEBERT, G. (Org.). Antropologia e velhice. Campinas: UNICAMP, 1994.

FINE, A. Leite envenenado, sangue perturbado saber médico e sabedoria popular sobre os humores femininos (séculos XIX e XX). In: MATOS, M. I. S de.; SOIHET, R. (Org.). $O$ corpo feminino em debate. São Paulo: UNESP, 2003. p. 44-57.

FOUCAULT, M. Hermeneutica del sujeito. La Piqueta: Madrid, 1990.

. A história da sexualidade II: o uso dos prazeres. Rio de Janeiro: Graal, 1994.

GASTALDO, E.L. A forja do homem de ferro: a corporalidade nos esportes de combate. In: LEAL, O.F. (Org.). Corpo e significado: ensaios de antropologia social. 2.ed. Porto Alegre: UFRGS, 2001. p. 203-227.

GROSZ, E. Corpos reconfigurados. Cadernos Pagu, n. 11, p. 45-86, 2000.

LAQUEUR, T. Inventando o sexo: corpo e gênero dos gregos a Freud. Rio de Janeiro: Relume-Dumará, 2001.

LAURETIS, T. A tecnologia do gênero. In: HOLLANDA, H. (Org.). Tendências e impasses. O feminismo como crítica da modernidade. Rio de Janeiro: Rocco, 1994.

LE GOFF, J. L'imaginaire médieval. Paris: Gallimard, 1991.

MARTIN, E. The egg and the sperm: how science hás constructed a romance based on stereotypical male-female roles. New York: Oxford University Press, 1996.

MARTIN, E. A mulher no corpo: uma análise cultural da reprodução. Rio de Janeiro: Garamond, 2006. 
MATOS, M.I.S de. Delineando corpos: as representações do feminino e do masculino no discurso médico. In: MATOS, M. I. S de.; SOIHET, R. (Org.). O corpo feminino em debate. São Paulo: UNESP, 2003. p. 107-128.

MATOS, A. A. de; LOPES, M.de F. Corpo e gênero: uma análise da revista TRIP para mulher. Estudos Feministas, v. 16, n. 1, p. 61-76, 2008.

NOVAES, J. de V. O intolerável peso da feiúra: sobre as mulheres e seus corpos. Rio de Janeiro: Garamond, 2006.

OHRBACH, S. Hunger strike: the anoretic's as a methaphor for our age. New York: Norton, 1985.

PERROT, M. Os excluidos da história: operários, mulheres e prisioneiros. 2. ed. Rio de Janeiro: Paz e Terra, 1992.

. Os silêncios do corpo da mulher. In: MATOS, M.I.S. de; SOIHET, R. (Org.). $O$ corpo feminino em debate. São Paulo: UNESP, 2003. p.13-27.

PETER, J.P. Les médecins et les femmes. In: ARON, J.P. (Org.). Misérable et glorieuse: la femme du XIX siècle. Paris: Fayard, 1980.

RODRIGUES, J.C. Tabu do corpo. 7.ed. Rio de Janeiro: Fiocruz, 2006.

ROHDEN, F. A construção da diferença sexual na medicina. Cad. Saúde Pública, Rio de Janeiro, n. 19, supl. 2, p. 201-212, 2003.

_. Uma ciência da diferença: sexo e gênero na medicina da mulher. Rio de Janeiro:

Fiocruz, 2001.

SAFFIOTI, H.I.B. Rearticulando gênero e classe social. In: COSTA, A. de O.; BRUSCHINI, C. (Org.). Uma questão de gênero. Rio de Janeiro: Rosa dos Tempos, 1992. p. 183-215.

SANT'ANNA, D.B. de. É possível realizar uma história do corpo? In: SOARES, C. (Org.). Corpo e história. 3.ed. Campinas: Autores Associados, 2006. p.3-23.

SCHIEBINGER, L. Skeletons in the closet: the first illustrations of the female skeleton. Berkeley: University of California Press, 1987.

SCHOTT, R.M. Eros e os processos cognitivos: uma crítica da objetividade em filosofia. Rio de janeiro: Rosa dos Tempos, 1996.

SILVA, M. da A.; MANDÚ, E. N. T. Ideias cristãs frente ao corpo, à sexualidade e contracepção: implicações para o trabalho educativo. Rev. Gaúcha Enferm, v. 28, n. 4, p. 459-464, 2007.

SWAIN, T.N. Velha? Eu? Auto-retrato de uma feminista. LABRYS: estudos feministas, n. 4, 2003. Disponível em: www.unb.Br/ih/his/gefen Acesso em: 09 jun. 2008.

VILA, A.C. Sex and sensibility: Pierre Roussel's systeme et moral de la femme. Representations, n. 52, p. 76-93, 1995. 


\section{Abstract}

The body and the construction of the unevenness of gender by science

This paper analyzes, from an unsystematic literature review, how the distinction between male and female body produced by science since the 19th century, especially through the discourse and practice of medicine, legitimate enunciators of bodily legitimate designs, can help make the construction of inferiority of the female body that legitimizes gender inequality in traditional societies that, somehow, still reproduce or remain in the contemporary world.

Key words: body; sex; gender. 